\title{
EVALI: A Review of the Vaping Related Lung Injury
}

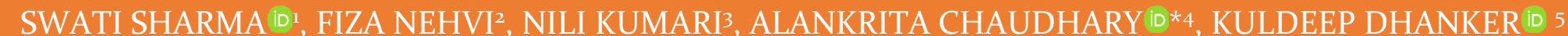

Vaping or e-cigarettes were introduced to help people quit smoking tobacco but with every passing year, their demand has dramatically increased as compared to the traditional cigarettes. With the increase in the number of vapers, an alarming vaping related outbreak which was given an official name by the CDC: EVALI (Electronic cigarette or Vaping Product Associated Lung Injury). In the United States, until January $21^{\text {st }}, 20202051$ cases have been reported from all 50 states with 60 deaths confirmed in 27 states and the district of Columbia. Not much is known about the cause of this outbreak but the possible culprits could be THC(Tetrahydrocannabinol) containing materials or Vitamin E Acetate. In order to protect the youth and the adults from such health hazards the government took a step by putting a ban on E-cigarettes. After the US states of Michigan \& New York, India too, imposed a ban on the sale of such e-cigarettes. This review paper discusses about e-cigarettes and about its harmful effects that lead to EVALI in a person.

KEYWORDS: E-cigarettes, Vaping, Smoking Cessation, ENDS

\section{INTRODUCTION}

Meant to be safer, harmless and having no-tobacco, the Electronic cigarette (e-cigarette) was first patented in 1967 by Herbert A. Gilbert from Beaver Falls, PA. ${ }^{1}$ They gained immense popularity after a Chinese pharmacist named Hon Lik introduced e-cigarettes in the Chinese market through his employer in 2004 and ever since, are freely available over the internet for users to buy and use. $^{2}$

These (e-cigarettes) are also commonly known as Electronic Nicotine Delivery Systems (ENDS) and is a product which is operated through a battery which helps deliver nicotine through inhalable aerosol generated from a nicotine-containing solution. The term "vaping" is associated with an e-cigarette use. Vaping is finding an increase in its use, especially among the young population as it gives a sensation as well as provides the same taste and feeling of inhaling smoke that mimicking smoking from paper cigarettes. Not just e-cigarettes, but vape pens and advanced personal vaporisers (MODS) too are the devices used for vaping.

They were initially used as an alternative to regular smoking and were initially considered safe to use. However, the health consequences, arising from the long-term use of these e-cigarettes, i.e. (1) Its efficacy as compared to combustible cigarette smokers to help them to reduce and/or stop smoking, (2) The extent of carcinogens in e-cigarettes and, (3) the role of these products in initiating and perpetuating nicotine dependence in teenagers and young adults has been debated constantly across the globe. ${ }^{3}$

There have been various cases reported of lung injury as a result of these e-cigarettes and in this context, on October $11^{\text {th }}, 2019,{ }^{4}$ The Centres for Disease Control and Prevention (CDC) in its morbidity and mortality weekly report issued have given an official name to the vaping related illness named: EVALI (E-cigarette or Vaping Product Associated Lung Injury). This review paper discusses about e-cigarettes and about its harmful effects that lead to EVALI in a person.

\section{WHAT IS AN E- CIGARETTE?}

An E- cigarette is a hand held powered vaporizer which includes hand to mouth action of smoking but without combustion of tobacco and are categorised in to three groups: disposable, rechargeable and modular.5 They have a battery powered vaporizer that uses a heating element to heat e-liquid, typically containing nicotine, from a cartridge that produces a chemical filled aerosol. The effectiveness of an e-cigarettes depends on a variety of factors which include battery strength, the nature of 
the circuit used, solutions/flavour used and the user's smoking behaviour, among others. Since they work by producing vapours, their effectiveness has a direct dependence on the product's competence to heat the solution into a state where it transforms into vapour. As a result, the battery's voltage and circuit strength are also crucial components. The stronger the voltage and circuit, faster will the solution heat up and vaporise, and more effective will be the product. Electronic Smoking Device aerisol (ESD) that operate using a single coil heating element produce much higher levels of toxins at higher temperatures than double-coil devices across different e-liquids that produce aerosol at lower temperatures.6

E-cigarettes contain nicotine cartridges with airflow sensors, but do not burn tobacco.7 Many e-liquids or ejuice comes in fruit flavours, making them appealing to kids. There are over 466 brands and 7764 unique flavours with about 242 new flavours added per month.8 Instead of cigarette smoke, the user inhales as an aerosol, commonly called vapour. ${ }^{9}$

\section{MARKET SHARE OF VAPE PRODUCTS}

As per a report, the number of vapers have alarmingly increased from 7 million (2011) to 41 million (2018). The FDA in 2018 reported that approximately 3.62 million students users belonged to middle and high schools in the USA itself. With a span of one year, the current ecigarette use (use on at least one day in the past 30 days) in the same study population increased from 11.7 to 20.8 percent. ${ }^{10}$

It has also been estimated that the number of adults who vape will reach almost 55 million by the year 2021 and the global market currently is estimated to be worth $\$ 19.3$ bn which is approximately three times higher as compared to $\$ 6.9$ bn five years ago. USA has the largest market share of vape products followed closely by UK. Market estimates have suggested that in 2014, there were at least 466 brands producing ecigarettes and by 2030 the global e-cigarette market would rise by 17 times.

\section{MARKET SHARE IN INDIA}

India has more than ten 100 million adult smokers, making it a huge lucrative and a potential market for ecigarette companies. A single disposable e-cigarettes ranges from $\$ 6$ to $\$ 12$ (INR 390-782) and the cartridge models are rechargeable and contain pre-filled cartridges starter kits, which usually range around $\$ 40$ to $\$ 60$ (INR 2600-3900). ${ }^{12}$ In India, there are 75 companies that were supplying these e-cigarettes on line. During 2015-16 to 2018-19 e-cigarettes worth $\$ 1,91,781$ were imported in India which were mostly imported from China, US, Hong Kong and Germany.

\section{EVALI: THE PROBABLE CULPRITS}

To educate vapers, Dr. Stanton Glantz, Director for the Center for Tobacco Control Research and Education at the University of California, San Francisco stated that "If you are somebody who is using an e-cigarette, you are breathing an aerosol of exhaled nicotine, ultra fine particles, volatile organic compounds and other toxins." ${ }^{14}$

An Electronic Smoking Device aerosol (ESD) is made up of high concentration of ultrafine particles and the particle concentration is higher than in conventional tobacco cigarette smoke. ${ }^{13}$ Exposure to fine and ultrafine particles may exacerbate respiratory ailments like asthma and constrict arteries which could trigger a heart attack. ${ }^{14}$ The compounds that have been identified in mainstream (MS) or second hand (SS) ESD aerosol include: Actaldehyde(MS), Benzene(SS), Cadmium(MS), Formaldehyde(MS,SS), Isoprene(SS), Lead (MS), Nickel(MS), Nicotine (MS,SS), NNitrosonornicotin (MS,SS) and Toluene(MS,SS). Short term exposure of propelene glycol a chemical that is used as a base in ESD solution and is one of the primary component in aerosol emitted by ESD causes eye, throat and airway irritation, whereas long term exposure can result in children developing asthma. ${ }^{15}$

Henderson TR et al. (1981) ${ }^{16}$ reported that heating propylene glycol changes its chemical composition and produces small amount of propylene oxide, a known carcinogen. Detectable levels of nitrosamines, diethylene glycol, glycerol, propanal, diactin and triactine have been reported in ESD aerosol ${ }^{17,18}$ Short term use of ESD has been shown to increase respiratory resistance and impair lung function, which may result in difficult breathing19 reported that ESD exposure especially to cinnamon damages lung tissues due to increased oxidative stress and inflammatory responses. Toxic chemicals attached to nanoparticles in ESD aerosol that are much smaller than the particle size in tobacco have adverse health effects than when these toxins are attached to large tobacco smoke particles. ${ }^{20}$

\section{CAUSES OF EVALI}

Since not much is known about the real cause of EVALI right now, it is believed that it might be an overlap with smoking related injuries or it might be a completely different phenomenon. However, the only difference 
was that many of the individuals who reported with the condition exclusively used vaping products and were not smoking the conventional cigarettes.

Officials at the CDC said that THC (Tetrahydrocannabinol) containing products may be behind this outbreak in lung illness related to vaping. THC is the key psychoactive compound that is found in marijuana which in turn is responsible for the feeling of being high. Around 16 percent of the sick patients claimed that they had used products that contained nicotine but not THC whereas 77 percent claimed of using products containing a mix of both. ${ }^{21}$ The CDC even has reported that these THC - containing products were obtained from informal sources like friends, family, or directly from the drug dealers (in Illinois and Wisconsin).

Another possible culprit that the CDC believes, which could be responsible for such chemical exposure rather than an infection has been identified as Vitamin E acetate.21 Vitamin $E$ acetate is a nutritional supplement that can be ingested as a vitamin supplement, or applied to the skin and is not know of causing any harm, however it is not approved as a vaping additive by $\mathrm{New}$ York State Medical Marijuana Program. The New York State Department of Health, after its thorough investigation stated that nearly all cannabis containing samples contained very high levels of this compound and no such traces were found in nicotine containing samples. ${ }^{21} \mathrm{CDC}$ is keeping an eye and still investigating the oil like compound which could be a possible culprit of EVALI.

\section{CASES REPORTED OF EVALI}

CDC, U.S Food and Drug administration (FDA), all state and the local health departments, and other clinical and public health sectors are investigating a multistate outbreak of the lung injury associated with e-cigarette, or vaping products. January $21^{\text {st }}, 20202051$ cases have been reported from all 50 states with 60 deaths confirmed in 27 states and the district of Columbia. Such an increase in the number of cases as well as mortality is the reason that CDC and other governmental agencies are directing their effort to prevent EVALI by either banning the ENDS or educating the public regarding the harmful effects of vaping.

As per CDC, approximately 90 percent of the cases that were reported with symptoms were hospitalized and many of them required supplemental oxygen, few of them had to be put on ventilator to help breathe while many had to be put on corticosteroids to reduce the lung inflammation. The cases reported with the signs and symptoms such as couching, shortness of breath, nausea, fatigue, weight, night sweats, low oxygen levels, and hazy spots on a lung X-ray. ${ }^{22}$ Such developments can be of extreme concern as most of the cases reported included teenagers or young adults. Some cases were characterised by pneumonitis (lung inflammation), some with accumulation of oil in the lungs, while others involved accumulation of white blood cells. ${ }^{23}$

\section{INDIAN SCENARIO}

In India till date no cases have been reported of EVALI, but that does not signify that the people of India who have been vaping are under no threat of developing the signs and symptoms of EVALI. The use of e-cigarettes prior to the ban by the population was increasing day by day and is it quite possible that the subjects reporting with symptoms could have been underreported by the patients to their attending doctors, or could have simply been associated with combustible tobacco use. The presence of air pollution could have also been a confounding factor (Especially in metropolitan areas where the AQIs are quite higher) in the proper diagnosis of EVALI and hence, no such cases have been reported till date.

\section{MEASURES TAKEN}

CDC is working day and night to identify the cause of the outbreak in collaboration with the states and other federal agencies. They even have activated the Emergency Operations Centre (EOC) to coordinate activities and to provide help to states, public health partners as well as the clinicians around the nation. By invitation the Epidemic Intelligence Service (EIS) officers and other CDC staff has been deployed by CDC. Few other range of laboratory investigation made possible by CDC and FDA include:

- Testing bronchoalveolar lavage (BAL) fluid samples along with the urine and blood samples paired to BAL fluid samples.

- Testing the pathological samples, that includes lung biopsy or autopsy specimen.

- Aerosol emission testing which will augment the ongoing work of FDA to characterize e-liquid and help in better understanding of the lung injury breakout.

- Apart from several laboratory investigations, Ban on the use of e-cigarette or other vaping products too have been imposed in several states globally. In the US, 
Michigan has become the first state to impose ban on flavoured e-cigarettes, with New York being the second state to impose the ban.

\section{INDIA}

A day after New York's ban, Modi government on $18^{\text {th }}$ September,2019 too announced a ban on e-cigarettes confirming the health risks they pose to the youth and the increasing addiction to be alarming.24 The government said, the main aim to ban e-cigarettes was protecting the youth, the section of the society which is most vulnerable to addiction and its health hazards.1 5 states and one union territory prior to any announcement being made, had already banned ecigarette which include, Punjab, Karnataka, Mizoram, Kerala, Jammu \& Kashmir, Uttar Pradesh, Bihar, Maharashtra, Tamil Nadu, Jharkhand, Himachal Pradesh, Pondicherry, Rajasthan, Meghalaya, Odisha, and Nagaland.

\section{FINES UNDER THE NEW LAW (INDIA)}

Once the law passed in 2019 comes into effect, certain provisions will be made applicable. ${ }^{23}$ The production, manufacture, import, export of e-cigarettes shall become an identifiable offence in India, which will be punished with an imprisonment of up to one year or fine up to 1 lakh or both for the first offence.

- The punishment of imprisonment up to 3 years and fine up to 5 lac, if someone caught disobeying the law again.

- Punishment of imprisonment up to 6 months or fine up to Rs 50,000 for those found storing e-cigarettes.

- The dealers that have existing stocks of e- cigarettes need to inform the nearest police station on their own before strict actions are taken against them.

\section{VAPING: AN ETHICAL DILEMMA}

e-cigarettes in the first place were introduced to help people quit smoking tobacco. However, there are no such studies that show vaping actually helps people quit smoking. In 2015 ,U.S surgeon general reported a hike in consumption of E-cigarette by $900 \%$, in which $40 \%$ users had never smoked the traditional cigarette. The traditional as well the $\mathrm{E}$-cigarette, both contain nicotine and can be equally addictive as cocaine or heroin. In fact, few of the e-cigarette users get more nicotine than the traditional ones as, extra strength cartridges are available which have a higher concentration of nicotine or a higher hit of the substance can be achieved by increasing the voltage of E - cigarette. Vaping is definitely less harmful than smoking the traditional cigarette, but still it is not safe. Hence electronic cigarettes are not the best smoking cessation tools.

\section{PREVENTION OF EVALI}

As vitamin E-Acetate is listed as a possible culprit of EVALI ,but evidence is not yet so substantial to rule out the contribution of other chemicals that are present in an E- Cigarette .Till then the CDC recommends all the people to consider refraining themselves from using $\mathrm{E}$ Cigarette or vaping, products. THC used very often has also being associated as another probable cause of EVALI ,so the people are recommended not to use THC containing E- Cigarettes, vapes, or other products in order to avoid any harmful effects it may pose. Population with Marijuana use disorder should seek medical help as it has other ill effects as well .Adults who are not tobacco consumers yet, should not start using E-Cigarette as they might consider it to be less harmful which is a persistent ethical dilemma in our society. Adults who continue to use E-cigarettes should keenly monitor themselves for any sort of symptoms and get the symptoms checked by a health care provider , if any resemblance found with those reported in the outbreak.

Adults using E-Cigarette as tobacco cessation method, trying to quit smoking are recommended to quit this habit and not going back to smoking the conventional ones rather considering using FDA approved nicotine replacement therapies.

\section{CONCLUSION}

With the CDC giving a name to the vaping related lung injuries, maximum-impact mass awareness programs need to be undertaken across the globe. Other countries should also report such cases so that significant conclusions regarding its aetiology and management can be established. If a complete ban is not feasible, a health warning among the packs should be made mandatory and any new flavour/product should only be introduced with necessary regulatory approvals so that the mortality and mortality associated with EVALI can be decreased.

\section{REFRENCES:}

1. Gilbert H. United States Patent Office. 1965. Accessed November 1, 2017. (Patent available online, last accessed on $15^{\text {th }}$ October, 2019)

2. https://www.whoinventedit.net/who-invented-theelectronic-cigarette.html [Last accessed $15^{\text {th }}$ November, 2019] 
3. Glantz SA, Bareham DW. E-Cigarettes: Use, Effects on Smoking, Risks, and Policy Implications. Annu Rev Public Health. 2018;39:215-35.

4. Farber M. CDC gives vaping related lung illness a new name: EVALI.(online article). Available from: https://www.foxnews.com/health/cdc-vaping-relatedlung-illnesses-name

5. Pasquale C, Davide C, Gabriella P, Cristina R, Riccardo P. The emerging phenomenon of electronic cigarettes. Expert Review of Respiratory Medicine. 2012:6(1):63-74.

6. Yingst JM, Veldheer S, Hrabovsky S, Nichols TT, Wilson SJ, Foulds J. Factors associated with electronic cigarette users device preferences and transition from first generation to advanced generation devices. Nicotine Tob Res. 2015;17(10):1242-6.

7. SEATCA_E-Cig (2014) Electronic cigarettes in Asia a review of promotions and availability. SEATCA_E-Cig.

8. Huey S. Escape the vape: Health hazards of the latest nicotine craze. Nursing 2018 47(1):46-51 .

9. Wieslander G, Norbäck D, Lindgren T. Experimental exposure to propylene glycol mist in aviation emergency training: acute ocular and respiratory effects. Occupational and Environmental Medicine 2001;58;10:649-55.

10. Heydari G, Ahmady AE, Chamyani F, Masjedi M, Fadaizadeh L, et al. Electronic cigarette or harmful for quitting smoking and respiratory health: A quantitative review papers. Lung India 2017;34(1):25-8.

11. Grana R, Benowitz N, Glantz SA. E-cigarettes: a scientific review. Circulation 2004;129: 1972-86.

12. IEC Vaping Authority (2018) E-cigarettes: A cost analysis-IEC Vaping Authority.IEC Best E-Cig and Vape Guides.

13. Fuoco FC, Buonanno G, Stabile L, Vigo P. Influential parameters on particle concentration and size distribution in the mainstream of e-cigarettes. Environ Pollut. 2014;184:523-9.

14. Grana R, Benowitz N, Glantz SA. E-cigarettes: a scientific review. Circulation 2014;129(19):1972-86.

15. Wieslander G, Norback D, Lindgren T. Experimental exposure to propylene glycol mist in aviation emergency training: acute ocular and respiratory effects. Occup Environ Med. 2001 Oct; 58(10): 649-55. 16. Henderson TR., Clark CR, Marshall TC, Hanson RL, Hobbs $\mathrm{CH}$. Heat degradation studies of solar heat transfer fluids. Solar Energy. 1981;27(2):121-8.

17. Cheng T. Chemical evaluation of electronic cigarettes. Tob Control. 2014;23:ii1-ii17.

18. Schripp T, Markewitz D, Uhde E, Salthammer T. Does e-cigarette consumption cause passive vaping?. Indoor Air. 2013;23(1):25-31.
19. Vardavas CI, Anagnostopoulos N, Kougias M, Evangelopoulou V, Connolly GN, Behrakis PK. Shortterm pulmonary effects of using an electronic cigarette: impact on respiratory flow resistance, impedance, and exhaled nitric oxide. Chest 2012;141(6): 1400-6.

2o. Mikheev VB, Brinkman MC, Granville CA, Gordon SM, Clark PI. Real-Time Measurement of Electronic Cigarette Aerosol Size Distribution and Metals Content Analysis. Nicotine Tob Res. 2016;18(9):1895-1902.

21. Radcliffe S. Deadly Vaping Illnesses Linked to THC Products. Online Article. Available from: https://www.healthline.com/health-news/vaping-

illness-top-400 [Last accessed on $16^{\text {th }}$ November, 2019] 22. Thielking M. Vaping-related illness has a new name: EVALI. STAT. Online Article. Available from: https://www.statnews.com/2019/10/11/vaping-related-

illness-has-a-new-name-evali/ [Last Accessed on $16^{\text {th }}$ November, 2019]

23. Rawat M. Explained: What are e-cigarettes? Why did the govt ban them? India Today. Online Article. Available from https://www.indiatoday.in/india/story/what-are-ecigarettes-why-have-they-been-banned-1600452-2019o9-18. [Last Accessed on $16^{\text {th }}$ November, 2019] 
Source of support: Nil, Conflict of interest: None declared

Cite this article as:

Sharma S, Nehvi F, Kumari N, Chaudhary A, Dhanker K EVALI: A Review

of the Vaping Related Lung Injury. Int Healthc Res J. 2020;3(12):370-375.

https://doi.org/10.26440/IHRJ/0312.03327

AUTHOR AFFILIATIONS: $\left({ }^{*}\right.$ Corresponding Author $)$

1. Associate Professor \& Head (https://orcid.org/oooo-0oo1-7181-5299)

2. Intern

3. BDS Final Year Student

4. *Reader (https://orcid.org/oooo-0oo3-2086-6779)

5. Assistant Professor (https://orcid.org/oooo-0002-5783-7229)

Department of Public Health Dentistry, School of Dental Sciences, Sharda University, Uttar Pradesh, India

Contact corresponding author at: alankrita.chaudhary@sharda.ac.in 